\title{
Trehalose monooleate: a potential anti- aggregation agent for stabilization of proteins
}

Smita S. Kale and Krishnacharya G. Akamanchi*

Department of Pharmaceutical Sciences and Technology, Institute of Chemical Technology, Mumbai, India 400019

\author{
Corresponding Author *_Prof. K. G. Akamanchi, Department of Pharmaceutical \\ Sciences and Technology, Institute of Chemical Technology, Mumbai, \\ India-400019.Tel: +91-022-33612214, Fax: +91-22-33611020 \\ E.Mail:kgap@rediffmail.com,kg.akamanchi@ictmumbai.edu.in
}

\section{Table of contents}

Figure 1. IR spectrum of TMO

Figure 2. ${ }^{1} \mathrm{H}$ NMR spectrum of TMO 


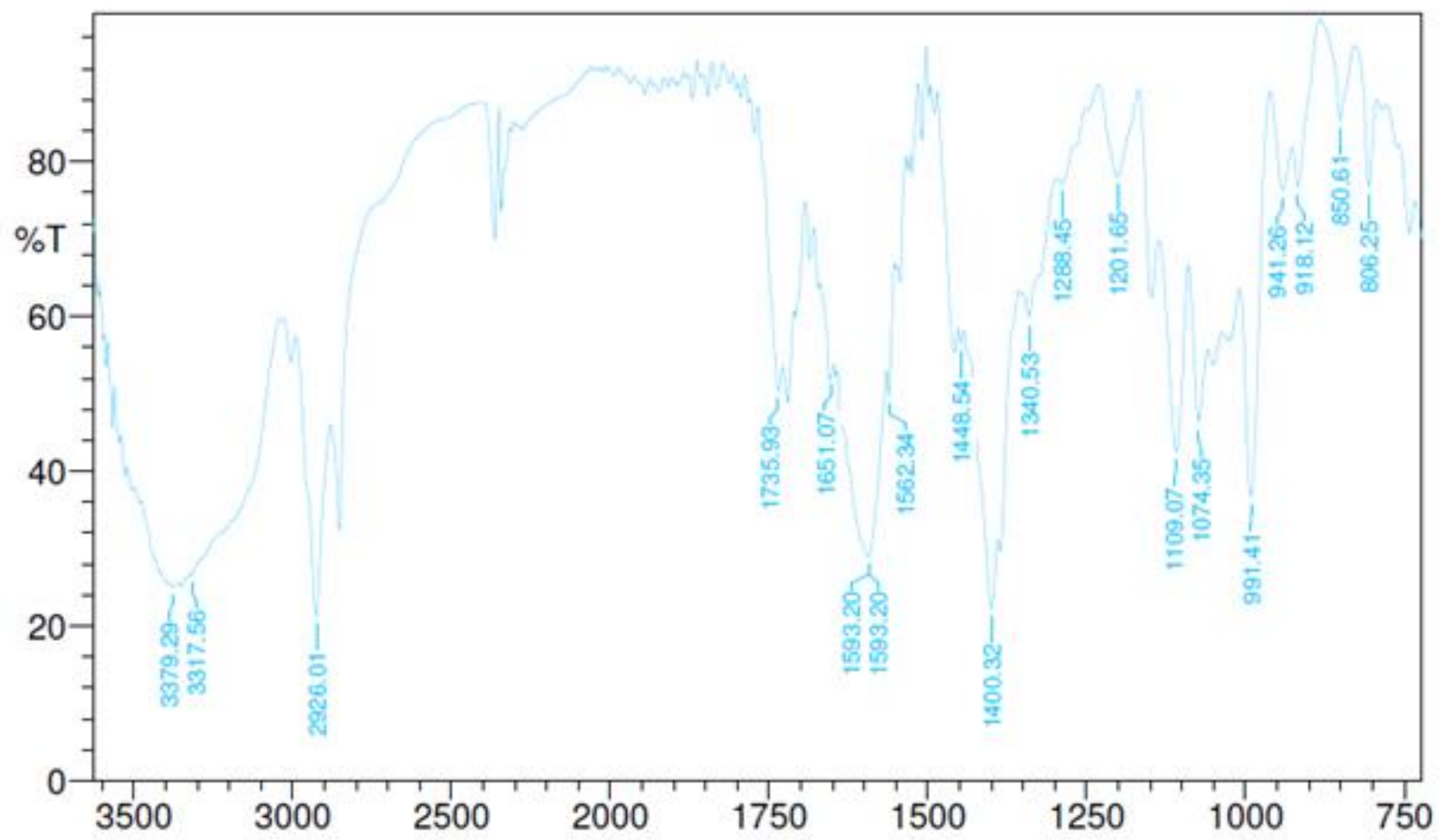

Figure 1. IR spectrum of TMO 


\section{TMO}

AAA PROTON MEOD

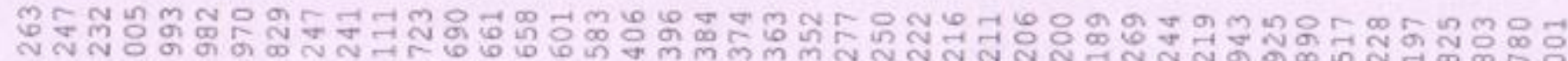

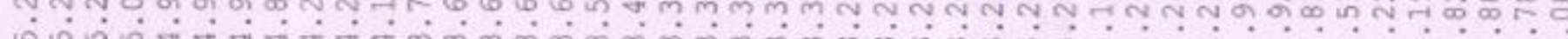
in th

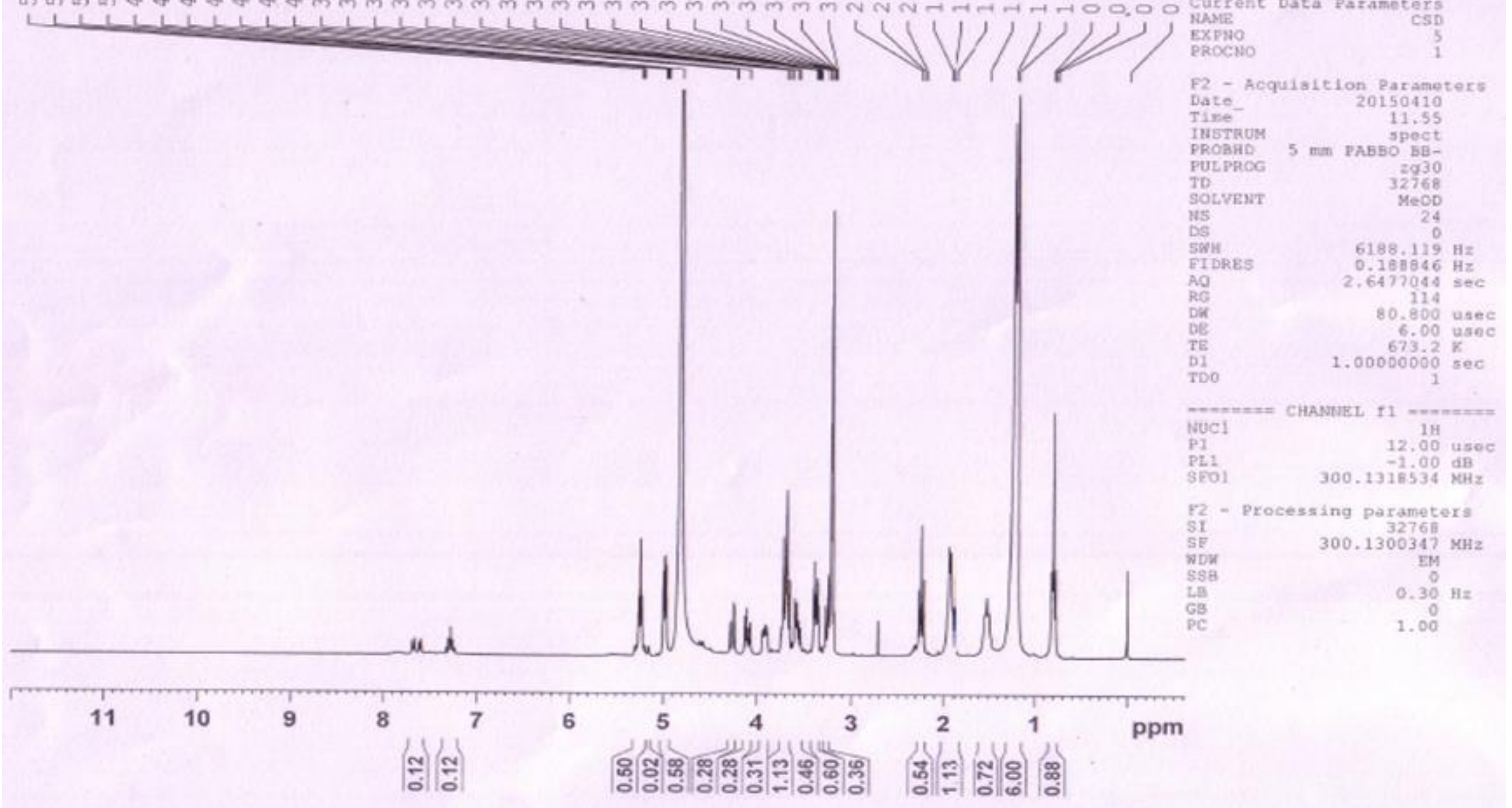

Figure 2. ${ }^{1} \mathrm{H}$ NMR spectrum of TMO 